\title{
ENGINE-IGNITION SHIELDING FOR RADIO RECEPTION IN AIRCRAFT
}

\author{
By H. Diamond and F. G. Gardner
}

ABSTRACT

The use of highly sensitive receiving equipment on aircraft has made the problem of airplane engine ignition shielding an important one. Ignition shielding consists of so confining the electrical fields of the ignition system that no interfering signal can be set up in the radio receiving circuits. The problem in ignition shielding is chiefly in the electrical and mechanical design of the arrangement for shielding, it being much more difficult to secure an assembly which will not adversely affect the engine-ignition system than to obtain complete freedom from interference for the radio equipment.

The bureau has been in active cooperation with airplane-engine, magneto, spark-plug, and cable manufacturers in an effort to develop a safe method for effecting this shielding and to make the necessary equipment available commercially. As a result of this cooperation shielding assemblies may now be purchased for use on all Wright and Pratt-Whitney airplane engines. A metallic ignition manifold is employed with high-tension cable drawn through it in the usual way. The leads from the manifold to the spark plugs and the groups of leads from the manifold to the magneto outlets are inclosed in liquid-proof flexible aluminum tubing with copper braid on the outside to insure effective shielding. Each flexible tubing is suitably fitted to the ignition manifold and to the magnetos or spark plugs, as the case may be. The magnetos are provided with covers which completely inclose the distributor blocks. A single outlet permits the use of an elbow fitting for connection to the large flexible metal tubing. This elbow fitting differs for different types of engines. Outlets are provided in the elbows for the booster and ground leads. The spark plugs are of a type in which the shield is an integral part and are provided with elbows for connection to the smaller flexible metal tubing. The ignition switch is totally inclosed in a metal cover, the booster magneto is also covered, and the leads from the magnetos to the ignition switch and booster magneto are inclosed in flexible metal tubing. The complete assembly insures electrical safety; mechanical sturdiness; liquid proofing of magnetos, spark plugs, and ignition cable; and ease of installation and of servicing.

\section{CONTENTS}

I. Introduction

II. Requirements for a practicable shielding assembly

III. Description of bureau's work

1. Early shielding assemblies........

2. Improved shielding assembly, manifold type

IV. Bonding of aircraft-Shielding of auxiliary electrical apparatus...-

V. Tests for practicability of shielding system

1. Test for shielding

2. Test of complete assembly for sparkover

3. Test for insulation resistance during and after exposure...-

4. Test for corona

\section{INTRODUCTION}

The increasing use of radio reception on aircraft for weather and navigational services has made the problem of airplane engineignition shielding of primary importance. To obtain full efficiency of operation of the sensitive aircraft receiving sets now available, it 
is necessary to eliminate the intense electrical disturbances set up in the radio-receiving circuits by the engine-ignition system. Ignition shielding consists of so confining the electrical fields of the ignition system that no interfering signal can be induced in the radio circuits.

The care which must be taken in ignition shielding depends entirely upon the ratio of the interfering signal of ignition ${ }^{1}$ induced in the receiving antenna to the radio signal required: This ratio is dependent upon the sensitivity of the receiving set employed, the type and location of the receiving antenna, and the frequency of the signal to be received. The more sensitive the receiving set, the smaller is the signal voltage required in the antenna for actuating whatever device may be connected in the receiver output. Since the voltage of the ignition interference is fixed for a given antenna, the interference-to-signal ratio is thus increased. On the other hand, assuming a fixed receiver sensitivity (hence, a fixed minimum useful received signal) the interference-to-signal ratio will depend upon the length of receiving antenna and its position with respect to the interfering source. Finally, since the source of disturbance consists essentially of a group of spark transmitters of varying high frequencies, the higher the frequency to which the receiving system is tuned, the greater will be the interference-to-signal ratio.

Within the past two years it has become common practice to use a vertical pole antenna with a highly sensitive receiving set for reception on aircraft. The requirements for ignition shielding have, therefore, become rigorous. To obtain effective shielding it becomes necessary to inclose the entire electrical system of the engine ignition in a high conductivity metallic shield. Therefore, the magnetos must be provided with such metallic covers as will completely inclose the distributing heads. The booster magneto must also be inclosed in metal. All distributing wires must be covered with a metal tube or braid. The spark plugs must be completely shielded. The booster leads, the leads to the ignition switch, and the ignition switch itself, must also be shielded.

\section{REQUIREMENTS FOR A PRACTICABLE SHIELDING ASSEMBLY}

The inclosure of the high voltage electrical system of the ignition in a closely surrounding grounded metallic casing introduces certain problems of electrical and mechanical design. It is much more difficult to secure an arrangement which will not adversely affect the engine-ignition system than to obtain freedom from ignition interference for the radio equipment. The factors which enter into the design of a safe and practicable shielding assembly may well be stated at this point.

1. Reliability of engine performance is the first consideration. The shielding must be such as to prevent insulation breakdown of any of the component parts of the ignition system. Full provision for the protection of the component parts from the effects of oil, gasoline, and water should be made. Mechanical protection of the ignition cable and other parts is necessary.

1 Where the engine is unshielded. 
B. S. Journal of Research, RP158

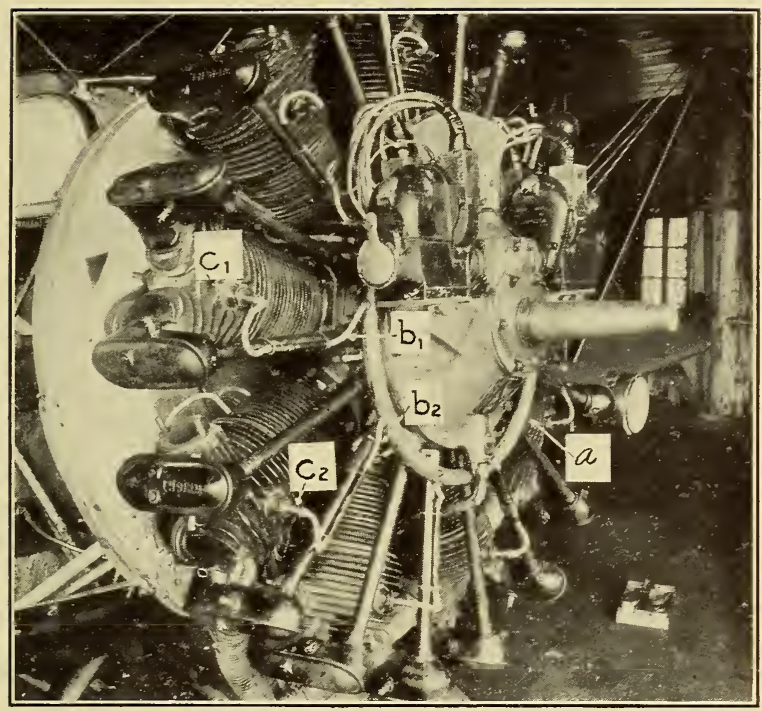

FIGURE 1.-Early shielding installation on Wright $J-\tilde{o}$ airplane engine

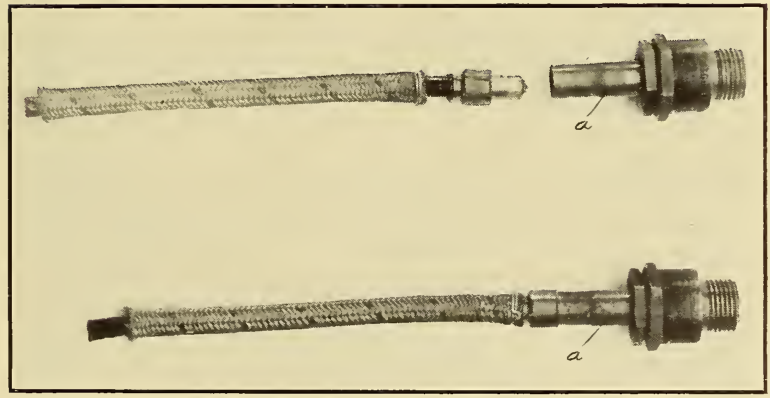

Figure 2.-Early type shielded spark plug 
2. Shielding of an effective and permanent nature is next in importance. The effectiveness of the shielding should not decrease with service. This requires a mechanically sturdy assembly.

3 . The shielding assembly must be satisfactory from an operating point of view. Servicing of the spark plugs and magnetos should be possible with a minimum of effort on the part of the operating staff. Replacements of individual leads or groups of leads should also be possible. Ordinary replacements should in no way affect the efficiency and completeness of shielding.

4. In addition to the above considerations, it is important that the component parts of the shielding be simple in their manufacture in order that the cost of radio shielding shall not be prohibitive.

This paper describes the experimental work carried on at the Bureau of Standards toward the development of a satisfactory and safe shielding assembly. Active cooperation was maintained in this problem with other Government departments, with manufacturing concerns and research organizations in the aircraft and radio industries, and with several air-transport companies. The final shielding assembly shown in Figures 17 to 21 , inclusive, which gives promise of fulfilling all the requirements for safe shielding, is a result of this cooperation.

\section{DESCRIPTION OF BUREAU'S WORK}

The bureau first became interested in the problem of ignition shielding in the winter of 1926-27, during the course of experiments on 2-way radiotelephony between aircraft and ground. However, the airplanes used in these experiments were equipped with watercooled Liberty engines and little difficulty was had in shielding these engines, a satisfactory shielding arrangement having already been developed by Army Air Corps engineers. Owing to the shape of this type of engine and of the cowling employed, shielding of the spark plugs was not required. A few months later, when it became necessary to provide shielding for transport airplanes equipped with radial-type air-cooled engines, the situation was found to be entirely different. It became apparent that the price which would have to be paid for the use of receiving sets having the necessary sensitivity to make a vertical pole antenna feasible, was the screening of the spark plugs. Moreover, such work as had previously been done on the shielding of radial-type engines had resulted in shielding installations hardly practicable for use on commercial transport airplanes. The bureau undertook to develop a suitable shielding assembly.

\section{EARLY SHIELDING ASSEMBLIES}

Several experimental installations were made in order to determine specifically the amount of shielding necessary and the nature of the technical difficulties encountered. The installation shown in Figure 1 (on a Wright J-5 engine) represents the first one considered at the time sufficiently practicable for transport use. For the purpose of mechanical protection of the high tension distributing leads, the original ignition manifold $(a)$ (supplied with the engine) was retained. Each distributing lead $\left(b_{1}, b_{2}\right.$, etc.) was separately shielded with closely woven copper braid and threaded through the manifold. The method 
of connecting the distributing leads to the shielded spark plugs $\left(c_{1}, c_{2}\right.$, etc.) may be seen in Figure 1 and in somewhat better detail in Figure 2. Figure 1 also shows the method employed for shielding the magnetos. The distributor blocks were individually covered with metal cans accurately fitted to the magneto castings to within 0.005 inch. Handmade covers using thin copper sheeting were employed in order to obtain a closer fit to the irregular magneto surfaces than was possible with the cast aluminum covers commercially available at the time. (See fig. 3.) The shielded spark plugs used were of a type developed jointly by the Navy Department and the B. G. Spark Plug Corporation, the shield being incorporated as an integral part of the spark plug. These were adopted only after considerable experimental work with metal covers for screening the plugs. Two types of shielding covers (figs. $4(a)$ and $(b))$ were employed in the preliminary experimental installations with successful results in so far as radio shielding was concerned. However, totally inclosing the spark plugs had resulted in their operation at temperatures in excess of normal.

To obtain effective shielding it was found necessary to inclose the ignition switch in a shielding can, as shown in Figure 5. Covering the terminal block of the booster magneto and shielding the switch and booster leads by means of closely woven copper braid completed the installation.

From a radio point of view, the shielding installation as described above was satisfactory. Not the slightest trace of ignition interference could be heard in the head telephones when using a receiving set having an over-all voltage amplification of about 1,000,000 to 3,000,000 . Practical difficulty was, however, experienced with this assembly. The magneto and spark plugs were not sufficiently protected from water. Short-circuiting of the spark plugs and of the magneto distributors during rain occurred. Furthermore, the over-all assembly was too frail mechanically. The method of connecting the distributing leads to the spark plugs introduced sharp bends in the leads exactly at their points of greatest exposure. Oil and dirt collecting on the metal braid at these points rendered the braid brittle. Whipping of the leads in the propeller slip stream resulted in breaks in the braid and in consequent decreasing effectiveness of shielding as well as in potential points of insulation breakdown.

Finally, the shielding assembly was faulty from the point of view of electrical design. Each lead being individually shielded, the capacitance per lead was from 400 to $500 \mu \mu \mathrm{f}$ as compared with 80 to 100 $\mu \mu \mathrm{f}$ for the lead unshielded. While a capacitance of 400 to $500 \mu \mu \mathrm{f}$ will not normally affect the magneto voltage sufficiently to interfere with the engine ignition, this is not necessarily true under certain abnormal conditions. Again, breaking of the small wires of the shielding braid, either in manufacture or in use, served to destroy the lacquered finish on the surface of the high-tension cable and produced points of brush discharge due to the interior current of the cable. The abrasive action of the metal braid on the cable also tended to injure the lacquered finish. This finish is necessary to protect the rubber of the cable against corona ozone that otherwise tends to rapidly destroy the rubber. The same film of lacquer protects the rubber against the effects of oil and moisture. With the lacquered film injured, faulty ignition occurred. The method of insulating the leadin wires to the shielded spark plugs was also found to be unsatisfac- 
B. S. Journal of Research, RP158

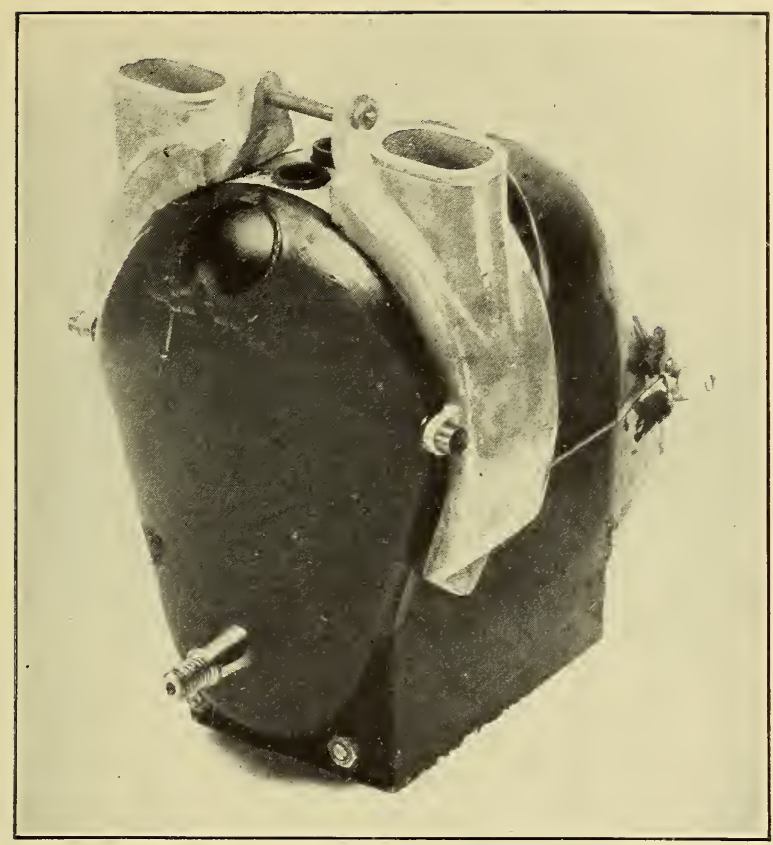

FIgure 3.-Early type shielded magneto

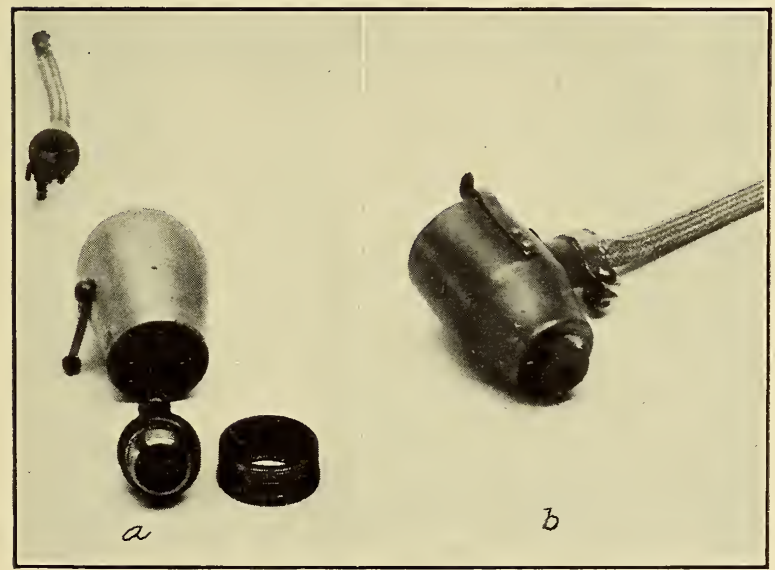

FIGURE 4.-Metal covers for shielding spark plugs 


\section{B. S. Journal of Research, RP158}

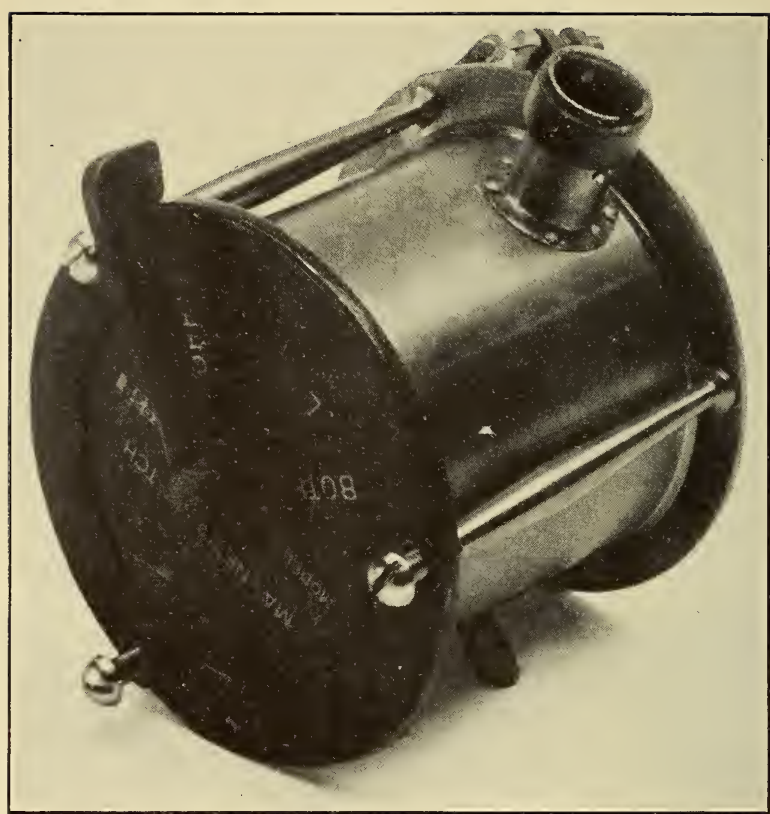

FIGURE 5.-Completely shielded ignition switch

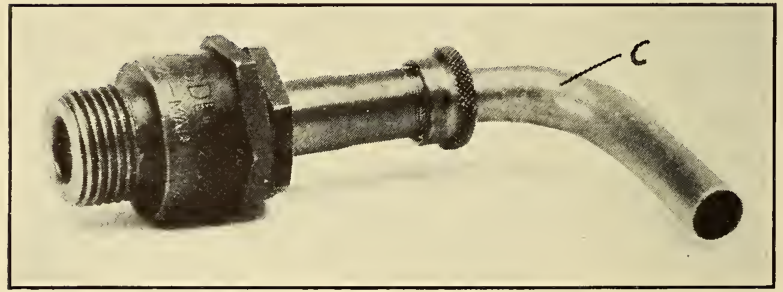

Figure 6.-Shielded spark plug provided with elbow fitting to insure liquid proofing 


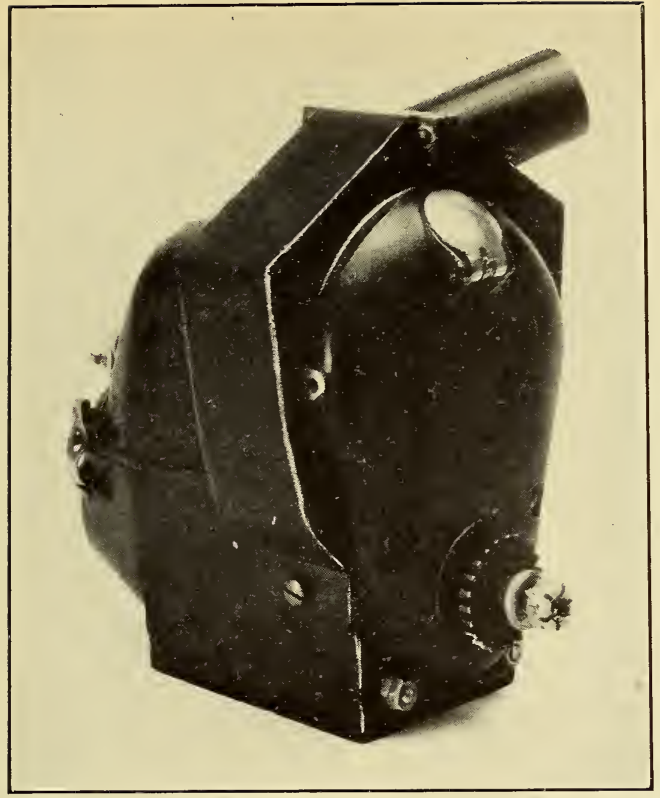

FIGURE 7.-Completely shielded magneto with single outlet for the ignition distributing leads

Liquid proofing is assure 1 by this arrangement for shielding.

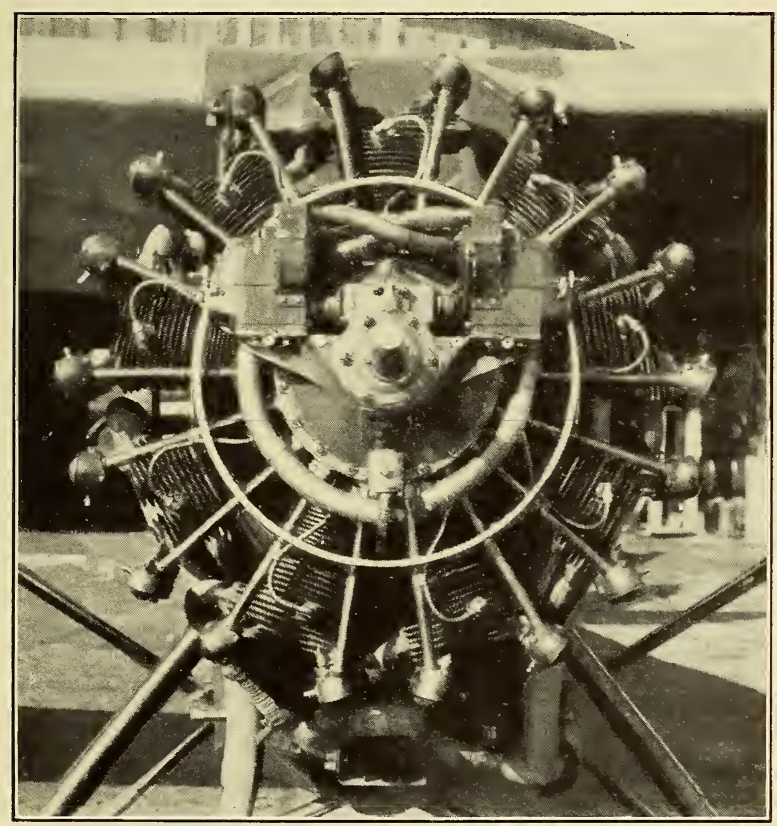

Figure 8.-Early shielding installation on Wright $J-5$ airplane engine

A special shielded ignition distributing harness is here employed. 
B. S. Journal of Research, RP158

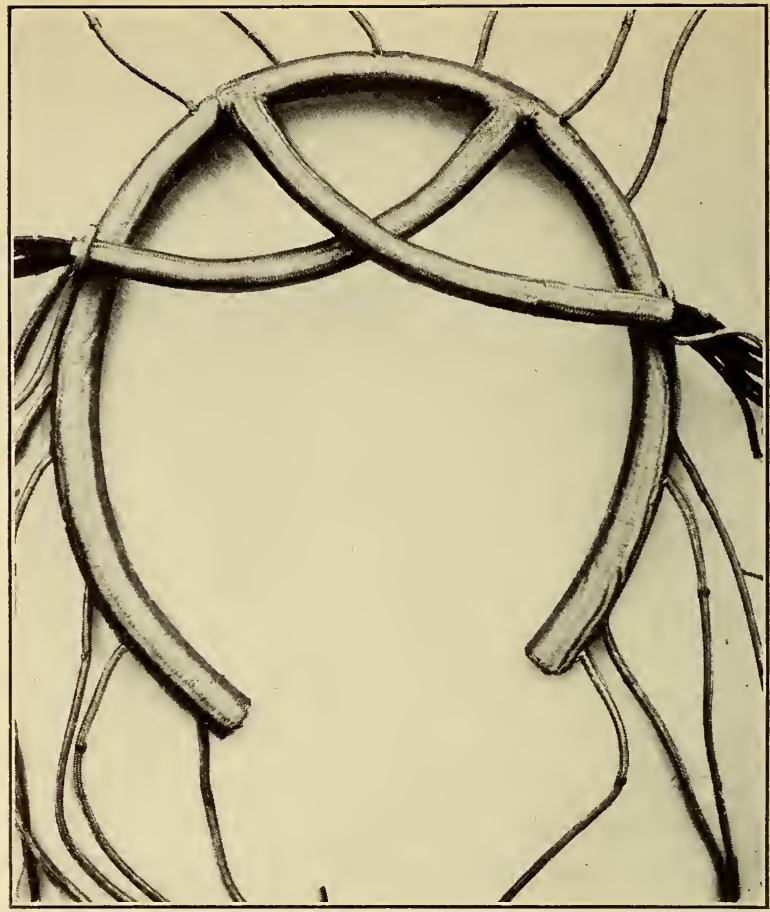

FIgURe 9.-Shielded ignition distributing harness used in installation of Figure 8

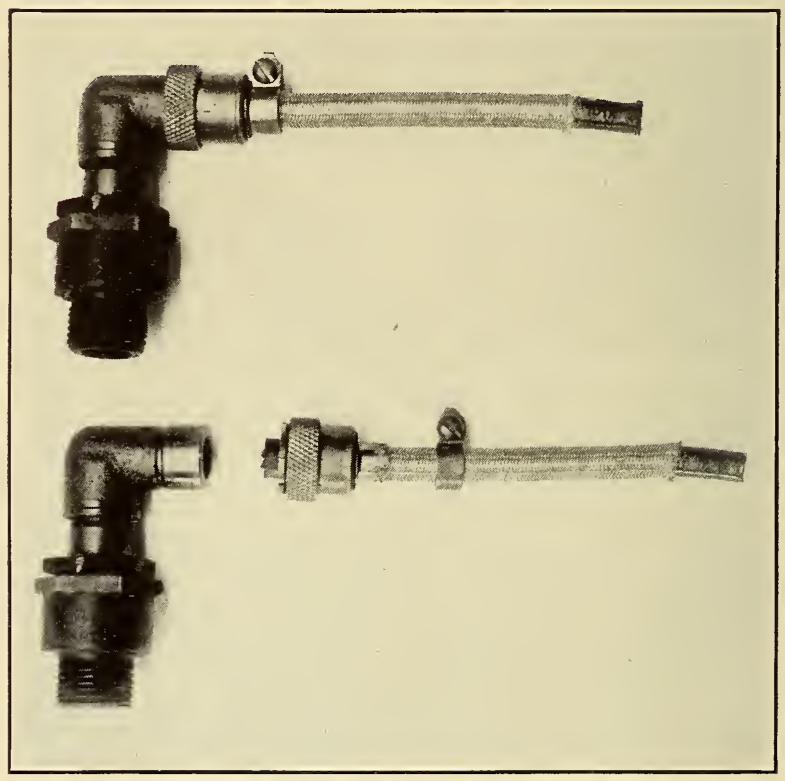

Figure 10.-Elbow type shielded spark plug used in installation of Figure 8 
tory. Thin mica sheeting rolled in the form of cigarette tubes serve as an insulating wall within the metal stem $(a)$ of the spark plug. (See fig. 2.) Flaking of the mica when taking the plugs apart for installation or inspection resulted in short circuits to the metal wall of the stem.

To provide better protection against rain for the spark plugs and magnetos, the arrangements indicated in Figures 6 and 7 were adopted. The aluminum elbow (c) Figure 6, was flanged so that with the knurled nut screwed tight, sealing of the spark plug against moisture was effected. The elbow also served as mechanical protection for the ignition leads at their points of maximum exposure. Whipping of the leads in the propeller slip stream was thereby prevented. The magneto distributing heads (fig. 7) were totally inclosed, a single outlet being provided for the nine ignition distributing leads. In addition to providing complete liquid proofing, this also served to improve the shielding of the booster and switch leads.

Simultaneously with this development, a second shielding installation was made on the bureau's experimental airplane (also equipped with a Wright J-5 radial-type air-cooled engine). A photograph of this installation is shown in Figure 8. A complete ignition harness (see fig. 9) developed through the cooperation of the Belden Manufacturing Co. was employed with the leads grouped together in a common ring. The nine leads to each magneto were also grouped. A closely woven copper shielding braid surrounded each group of wires, liquid-proof loom being used as a cushioning fabric between the groups of wires and the copper braid. Braiding the individual leads from the ignition harness to the spark plugs was still employed. The grouping of the leads and the use of shielding braid around the groups rather than on individual leads relieved considerably the added dielectric stress on the ignition cable due to shielding. It also served to decrease the capacitance to ground of each ignition lead, an average value of $160 \mu \mu \mathrm{f}$ per lead being obtained as compared with 400 to 500 $\mu \mu f$ per lead in the other type of installation.

The shielded spark plugs used were of an improved type, the B. G. Spark Plug Corporation having modified their early design in order to incorporate the features found essential in the bureau's tests. A photograph of the new design (showing also the method of connecting the ignition lead) is given in Figure 10. The crosssectional diagram of Figure 11 shows the details of assembly. The feature of right-angle entrance of the ignition lead was found very satisfactory from an installation and maintenance viewpoint. It was made possible, however, only after considerable experimental work on the part of the manufacturer, the provision of continuous insulation within the elbow proving particularly difficult. The type of shielded magneto employed is shown in Figure 12. For convenience in installation, the single outlet for the nine distributing leads was brought out on the side rather than on top of the shielding cover.

While this second shielding assembly proved somewhat more durable in service than the first type described, the wire braid over the portions of the ignition cable from the shielding harness to the spark plugs continued to be a source of trouble. The braid acted like a wick to hold oil or water and to lead it along the cable to the spark plugs. Sealing the spark plugs against moisture proved difficult. Moreover, the oil being held in contact with the rubber 
insulation of the cable rapidly deteriorated the rubber (whenever the lacquered film was broken). Faulty ignition then occurred. It was found necessary to replace the ignition harness after only 30 hours of operation. By winding oil tape over the shielded wire (see fig. 13), the life of the second harness was increased to about 50 hours.

The necessity for replacing the complete ignition harness because of faults developing in several leads demonstrated that it was economically unsound to use an assembly of this type. It became evident that an important requirement for a shielding assembly was that the individual leads should be readily replaceable. It was also apparent that some method of shielding the individual leads from the

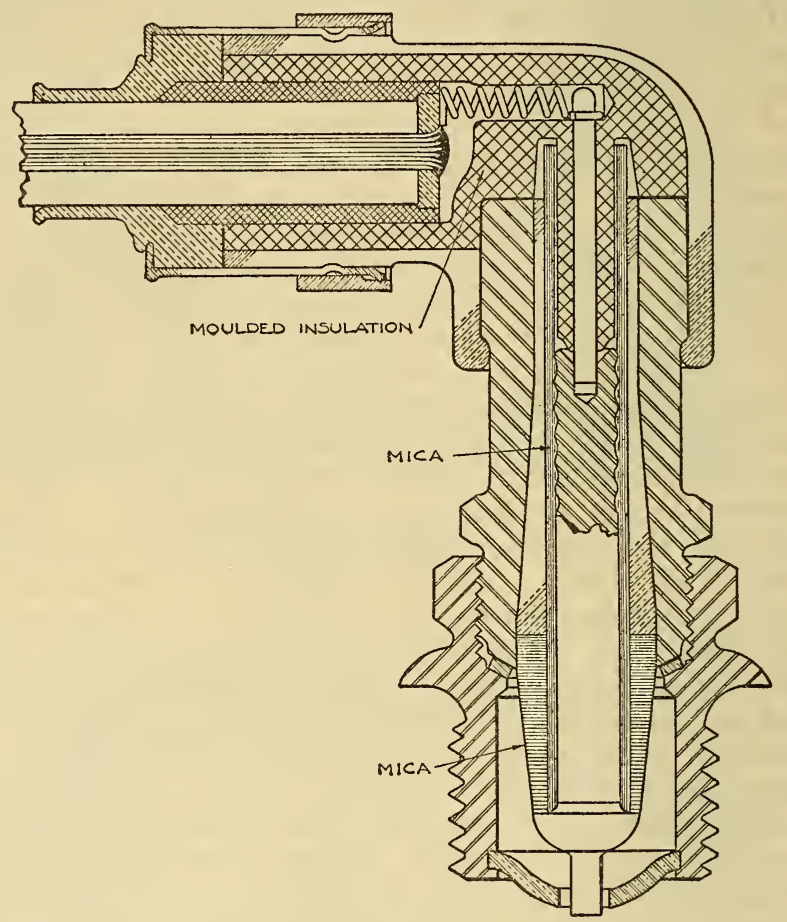

FigURE 11.-Cross section of elbow type shielded spark plug

ignition manifold to the spark plugs other than by the direct application of metal braid over the high-tension cable was necessary.

\section{IMPROVED SHIELDING ASSEMBLY, MANIFOLD TYPE}

At about this time a cooperative program on ignition shielding was begun with the Wright Aeronautical Corporation, the Pratt-Whitney Aircraft Co., and the Breeze Corporations. The engineers of these companies were in agreement with the conclusions drawn from the bureau's experiments. A joint study of the situation resulted in the shielding installation shown in Figure 14. A metal manifold ring was employed, with unshielded high-tension cable drawn through it in the usual way. To complete the shielding of the ignition leads from the manifold to the spark plugs, each lead was inclosed in a 


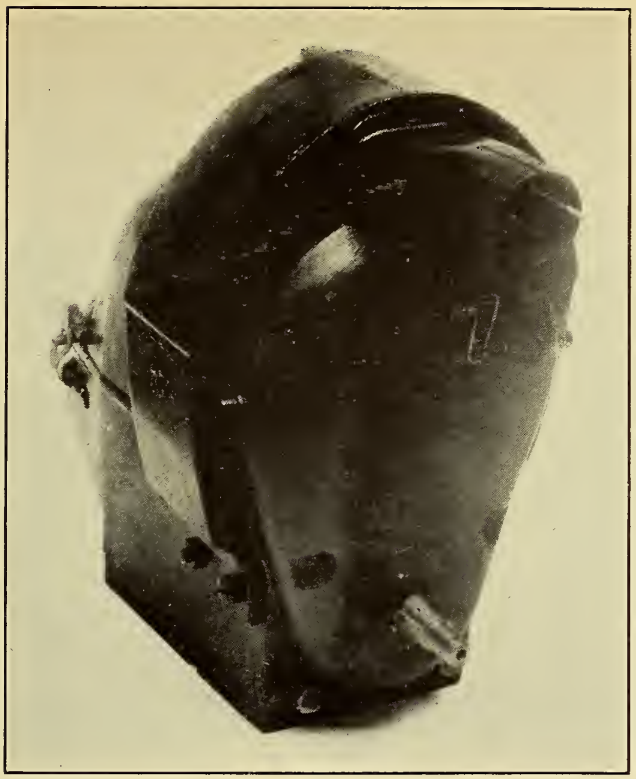

Figure 12.-Completely shielded magneto used in installation of Figure 8 with side entrance for the ignition distributing leads

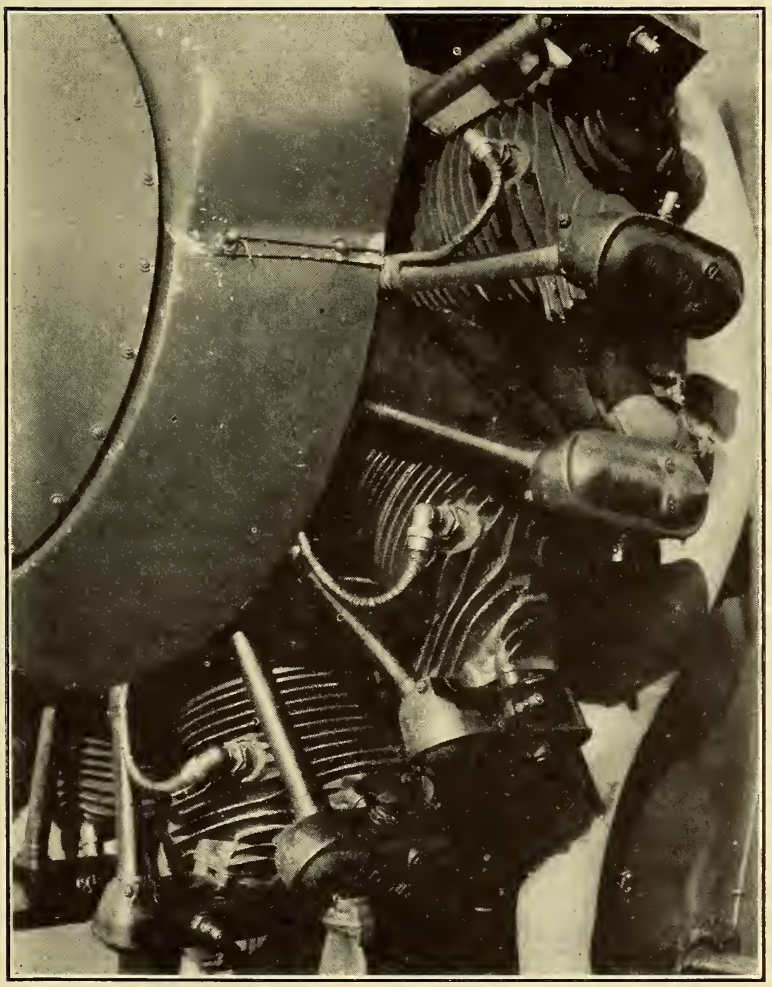

FIGURE 13.-Photograph showing the method used in the installation of Figure 8 for protecting the ignition leads against the effects of oil, water, etc. 
B. S. Journal of Research, RPI58

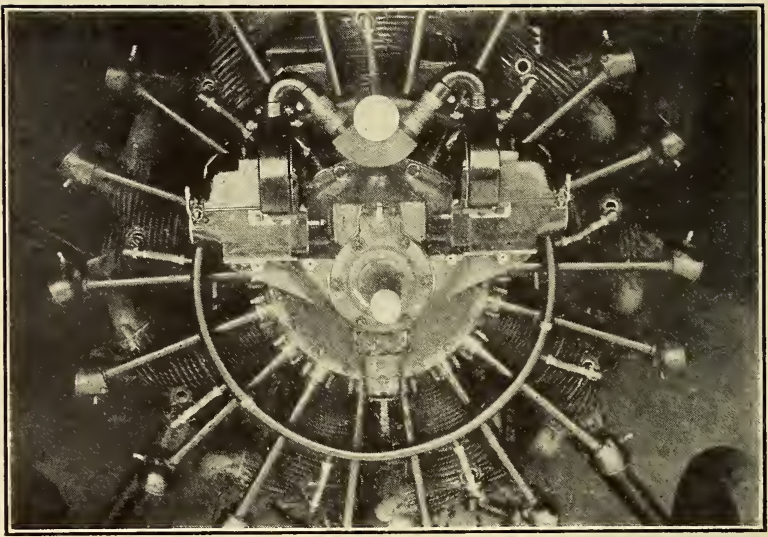

Figure 14.-Improved shielding installation on Wright $J-5$ airplane engine

Flexible metal tubing is used for shielding the exposed portions of the ignition cable.

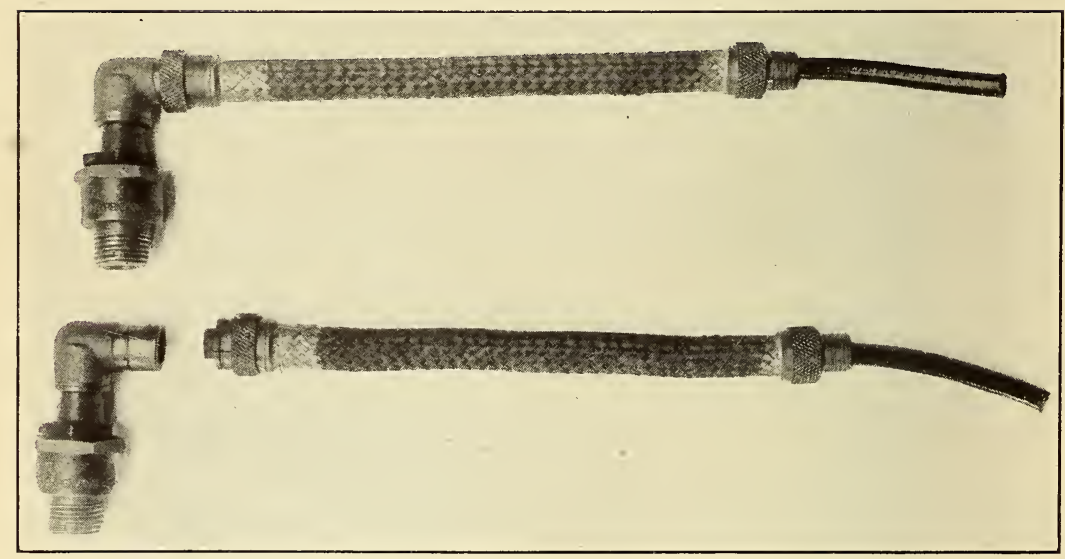

FIgURE 15.-Arrangement for connecting the flexible metal tubing to the elbow type shielded spark plug 
liquid-proof flexible aluminum tube, which was provided with a threaded fitting at one end for attachment to the mainfold and with a cap fitting at the other end for attachment to the shielded spark plug. The groups of leads from the manifold to the magneto outlet were similarly inclosed in flexible aluminum tubing of proper size. This larger tubing was connected to the manifold through a suitable union box and to the shielded magneto by means of an elbow fitting. To insure efficient shielding, it was considered desirable to surround the flexible tubing with closely woven copper braid.

The shielded spark plug used was of the B. G. elbow type. The method of connecting the flexible aluminum tubing to the spark plug may be seen from Figure 15. Servicing of the spark plugs is obviously very easy.

The magneto shielding employed (see fig. 16) was developed through the cooperation of the Scintilla Magneto Co. The feature of complete liquid proofing, found desirable in the bureau's tests, was incorporated in this design. The irregular surfaces of the magneto which had made liquid proofing difficult in the experimental models (see figs. 7 and 12) were eliminated by the use of new castings, special grooves being provided in these castings to insure a liquid-tight joint for the shielding covers. A split shielding cover with an auxiliary elbow fitting was adopted, making possible the inspection of either distributor block without removing the cover from the other block. This also permitted the use of different shaped elbows to suit installations on different engines, The small outlets $\left(a_{1}, a_{2}\right)$ for the leads to the booster magneto and the ignition switch were also split. An inspection of the magneto is thus possible without the necessity for disconnecting a single lead.

The use of flexible metal tubing was extended to the shielding of the booster and switch leads, the added mechanical protection for these leads being considered desirable.

The advantages of the manifold type shielding assembly described above are obvious. The assembly provides full mechanical protection for the component parts of the ignition system; liquid proofing of the magnetos, spark plugs, and ignition cable; and ease of installation and of servicing. The electrical design is also sound. The ignition cable is subjected to as low dielectric stress as is possible with a completely shielded system. The average capacitance per lead is comparatively small $(180 \mu \mu \mathrm{f})$.

Two installations were made using this type of shielding, one on the bureau's experimental airplane and one on a transport airplane. Both gave very satisfactory service with not a trace of faulty ignition. On the transport airplane, special test flights were made during rain, and satisfactory operation was had.

The success obtained with the manifold type shielding assembly led to the commercial development of an assembly having the same fundamental design. Shielding for the Wright J-5 and J-6 engines and for the Pratt-Whitney Wasp engines has thus become commercially available. Several improvements over the bureau's design are of interest. Figure 17 is a photograph of the commercial product for a Pratt-Whitney Wasp engine. Note that the union box for connecting the large flexible metal tubing to the manifold ring has been eliminated. This removes the possibility of damage to the insulation of the ignition cable due to sharp edges, Note also that the elbow 
fitting of the shielded magneto provides outlet for the booster and switch leads. This permits the use of the convenient arrangement shown in Figure 18 for shielding these leads. The shielded spark plugs shown in Figure 17, and in somewhat better detail in Figure 19, differ from the B. G. elbow type in the manner in which the insulation within the elbow is provided. Instead of molding the insulation within the metal elbow, a nickel-plated isolantite elbow is used. Either type of shielded spark plug may be employed in the assembly of Figure 17. Since weight is an important consideration in the design of equipment for aircraft, it is interesting to note that the weight added to the ordinary ignition assembly in order to provide complete shielding as well as liquid proofing is but 5 to 6 pounds.

Figure 20 shows the installation of a shielding harness of the commercial type on the bureau's experimental airplane, which is now equipped with a Wright J-6 engine. The shielding of the booster and switch leads is shown in Figure 21. The shielded ignition switch is not shown.

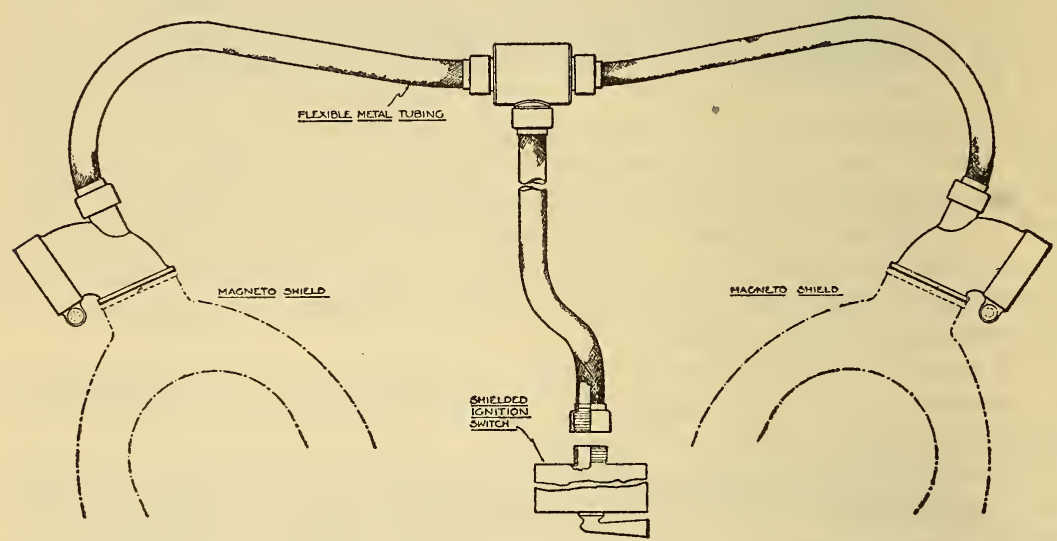

FIGURE 18.-Diagram showing the use of flexible metal tubing for shielding the booster and switch leads

\section{BONDING OF AIRCRAFT-SHIELDING OF AUXILIARY ELECTRICAL APPARATUS}

Additional sources of disturbance exist on aircraft other than the engine-ignition system. Ineffective bonding of the airplane is often the cause of interference with the radio receiving apparatus. By bonding is meant the interconnection of all metal parts of the aircraft by means of electrical conductors. If bonding is not provided, noises may be produced in the radio receiver due to sparks occurring between two metal members having a difference of potential due to the collection of static charges. Varying resistance between rubbing or vibrating metal parts is also a cause of noises in the radio receiver.

Complete specifications for bonding are given in Technical Order No. 08-5-1, Office of the Chief of Air Corps, War Department, Washington, D. C.

A certain amount of noise in the receiving set output may result owing to commutator sparking of the generator used for battery charging or for supplying power to transmitting apparatus and 
B. S. Journal of Research, RP158

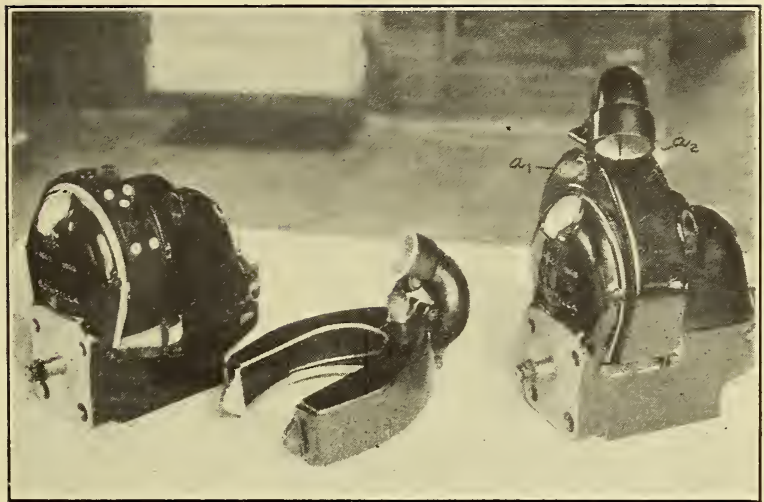

FIGURE 16.-Completely shielded magneto with single vertical outlet for the ignition distributing leads

A special elbow fitting is employed which may be varied to suit different installations.

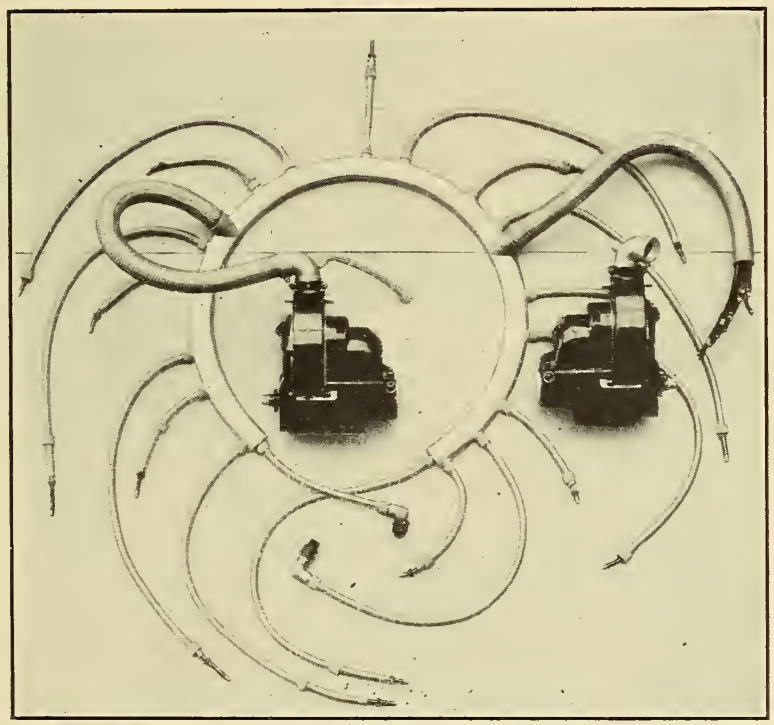

Figure 17.-Commercial shielding assembly for PrattWhitney Wasp engine, patterned after assembly shown in Figure 14 
B. S. Journal of Research, RP158

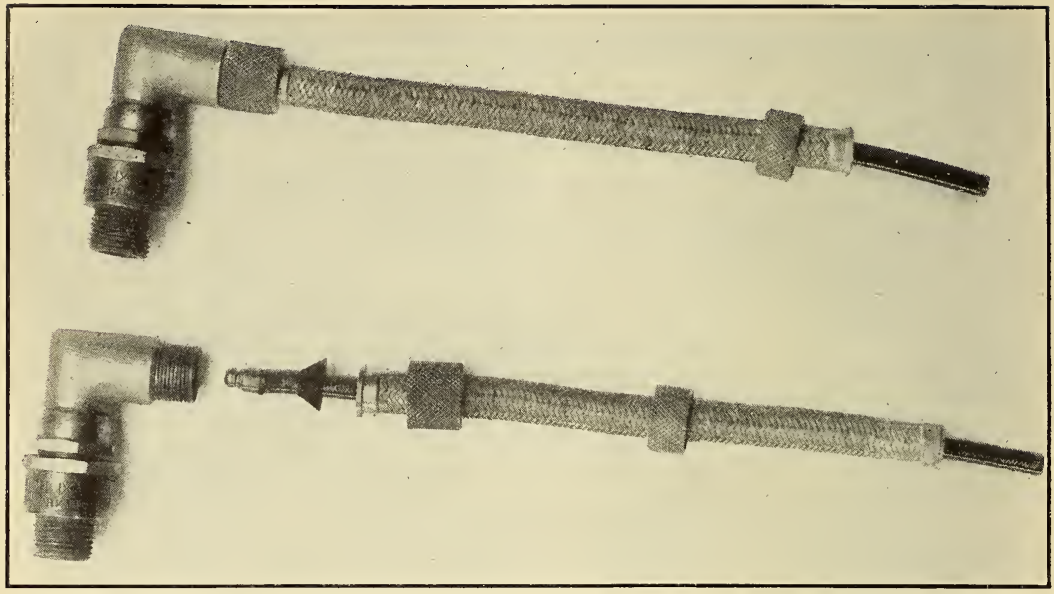

Figure 19.-Elbow type shielded spark plug using nickel-plated isolantite elbow

Note the arrangement for sealing the spark plug against moisture.

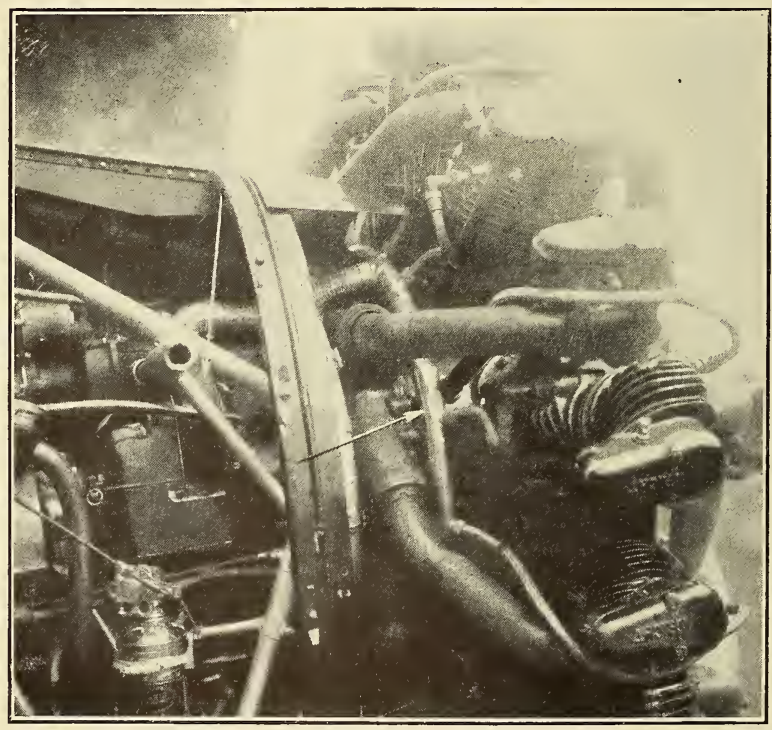

FIGURE 20.-Installation of the commercial type shielding assembly on bureau's Wright $J-6$ airplane engine 


\section{B. S. Journal of Research, RPI58}

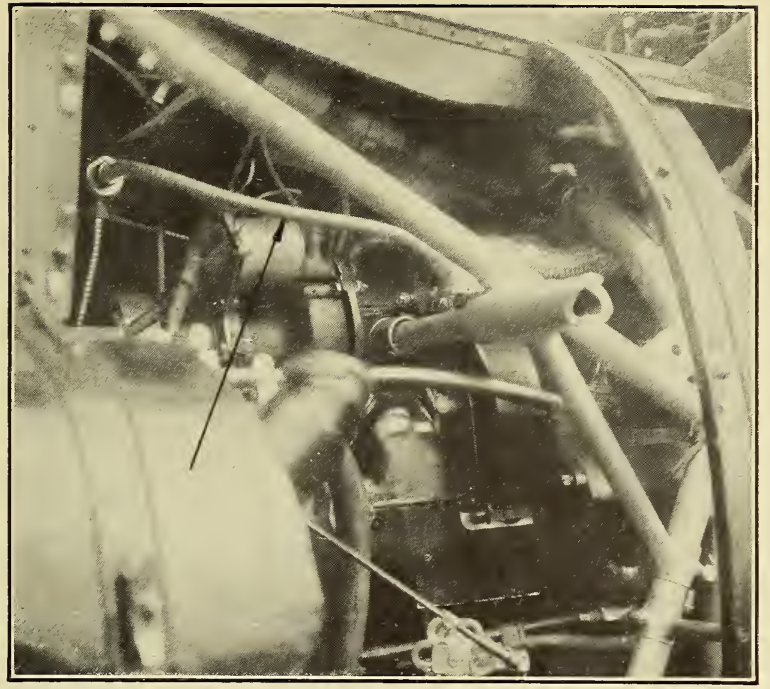

Figure 21.-Arrangement employed for shielding the switch and booster leads

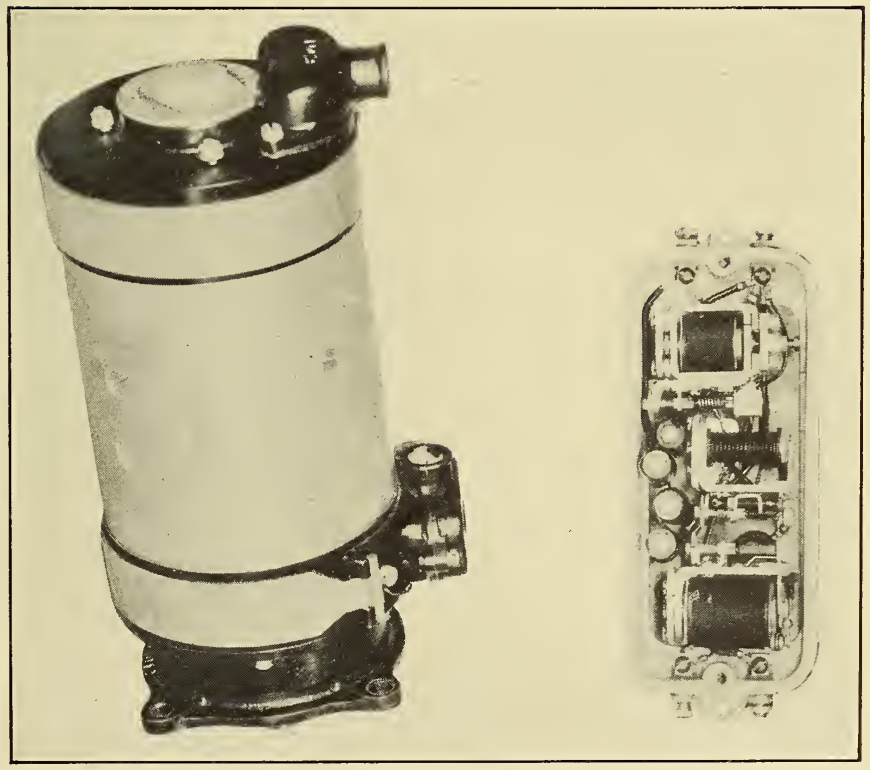

Figure 22.-Completely shielded double-voltage generator and control box 
receiving apparatus on aircraft. The sparking of the vibrating type voltage regulators used with these generators is an additional source of disturbance. Wherever possible, any piece of apparatus in which a spark occurs should be completely inclosed in metal. A photograph of a shielded generator and control box is given in Figure 22. Completely inclosing the generator is, however, not sufficient, since the disturbance may be carried by way of the leads from the generator. This requires shielding of all the leads. If the generator serves as a source of supply for the receiving equipment, suitable filter units must be employed in addition, to keep the commutator noises out of the radio receiver.

Further information on this subject may be obtained by reference to mimeographed notes ${ }^{2}$ on the "Minutes of conference on airplane engine ignition shielding held at the Bureau of Standards, June 11, 1929." This conference was called by the Bureau of Standards in response to a number of requests from representatives of the aircraft and radio industries. The purpose of the conference was fourfold:

1. To coordinate the experience and knowledge of the numerous organizations interested in this problem.

2. To formulate the requirements essential to safe shielding.

3. To stimulate the standardization of shielding assembly practice.

4. To set up standard tests whereby the mechanical, electrical, and radio efficiency of a given shielding installation may be determined.

\section{TESTS FOR PRACTICABILITY OF SHIELDING SYSTEM}

It is to be emphasized that the manifold type of shielding assembly described in this paper is not necessarily the only practicable solution of the problem of ignition shielding. The problem may be approached from numerous angles, so that other solutions entirely as practicable are possible. For this reason a set of standard tests was tentatively adopted at the conference on ignition shielding whereby the practicability of any shielding assembly, no matter of what type, may be determined. These tests are outlined below. The usefulness of these tests is now under investigation.

\section{TEST FOR SHIELDING}

The best test for radio shielding is the actual use of the shielding assembly mounted on the airplane engine. The radio receiving set must be suitably installed on the airplane, with an antenna of at least 6 feet extending vertically above the fuselage, and must be adjusted to maximum sensitivity. The receiver should have an over-all voltage amplification of the order of $1,000,000$ to $3,000,000$. If the shielding is complete, no ignition noise should be heard in the headphones (connected in the output of the receiver) for all engine speeds and for all tuning adjustments of the receiver. In this test it is understood that the engine is functioning normally in every way (that is, sparkplug gaps properly adjusted, etc.), that the noise level in the receiving set output due to atmospheric disturbances is normal, and that the airplane itself is suitably bonded and all auxiliary apparatus, such as generators, voltage regulators, or any other circuit wherein a spark occurs, are effectively shielded.

${ }^{2}$ Copies of these notes may be obtained on application to the radio section, Bureau of Standards, Washington, D. C.

$92380^{\circ}-30-7$ 


\section{TEST OF COMPLETE ASSEMBLY FOR SPARKOVER}

This test, together with the two following tests, should be made previous to installing the shielding assembly on the airplane engine. In this test the ignition leads are inclosed in the shielding manifold and terminate in the magneto distributor blocks with shielding covers at one end and in the shielded spark plugs at the other end. All connections between the component parts of the shielding assembly must be the same as when installed on the airplane engine. Provision should be made to ground the shielding assembly at points corresponding to grounds made when installed on the airplane engine. The magnetos are not used in this test in order to prevent damage to them. Mica insulators should be placed between the spark-plug points to prevent sparking at the test voltage to be employed. A voltage of 15,000 volts effective (of 60-cycle or higher frequency) should then be applied between all the ignition wires in parallel and the ground for a period of five minutes. Under this condition no sparking should occur. The condition of sparking may be determined by a sudden increase in the deflection of an indicating instrument connected in series with the above circuit. A regulating resistor is then also necessary to prevent burning out of this instrument.

\section{TEST FOR INSULATION RESISTANCE DURING AND AFTER EXPOSURE}

The same set-up as in the previous test shall be employed, except that the mica should be removed from the spark-plug gaps and provision made to protect the interior of the spark plugs from moisture. The complete assembly should be subjected to a spray of water for a period of three hours and readings of the insulation resistance of the individual leads to ground taken at intervals of one hour during this exposure. At no time should the insulation resistance of any lead to ground be less than 1 megohm.

\section{TEST FOR CORONA}

A suitable length of high-tension cable shielded in exactly the same way as the ignition leads extending from the main portion of the ignition manifold or casing to the spark plugs, and flexed at the least radius of curvature used shall be subjected to a voltage of 15,000 volts effective (60 cycles or higher in frequency) between conductor and shield for a period of two hours. Under this condition no sparking should occur.

Washington, October 9, 1929. 